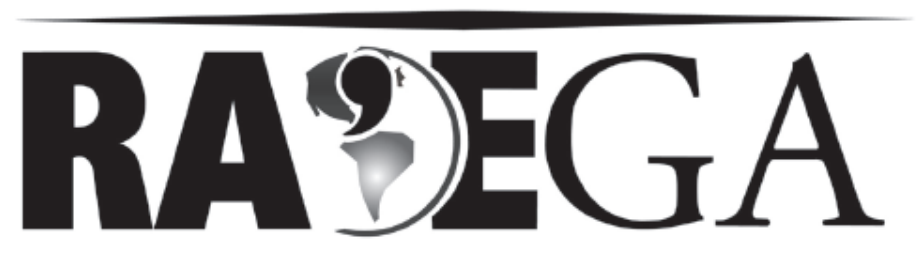

O ESPAÇO GEOGRÁFICO EM ANÁLISE

\title{
HEMEROBIA DAS PAISAGENS: CONCEITO, CLASSIFICAÇÃO E APLICAÇÃO NO BAIRRO PICI - FORTALEZA/CE
}

\section{LANDSCAPE'S HEMEROBY: CONCEPT, CLASSIFICATION AND APPLICATION IN THE DISTRICT OF PICI - FORTALEZA/CE}

\author{
Anderson Luiz Godinho BELEM ${ }^{1}$ \\ João Carlos $\mathrm{NUCCl}^{2}$
}

\section{RESUMO}

A ocupação humana das paisagens geralmente despreza os benefícios que a natureza pode fornecer e substitui esses benefícios por serviços executados com base na tecnologia e alto consumo de energia. Paisagens com alta dependência tecnológica e energética para a sua manutenção, com baixa capacidade de auto-regulação e baixo aproveitamento das funções da natureza apresentam alta hemerobia. A identificação da hemerobia é uma ferramenta para a reflexão sobre os tipos e intensidades das transformações antropogênicas das paisagens. A pesquisa apresenta um estado da arte dos estudos sobre hemerobia, sugere critérios para a avaliação da hemerobia de paisagens urbanizadas e em escalas mais detalhadas e aplica essas sugestões no bairro Pici (Fortaleza-CE).

Palavras chave: Hemerobia; Planejamento da Paisagem; Bairro Pici.

\footnotetext{
${ }_{1}^{1}$ Geógrafo e mestrando em Geografia (DGEOG-UFPR) andebelem@gmail.com

2 Biólogo (IB-USP), doutor em Geografia Física (DG-FFLCH-USP), professor do Departamento de Geografia da UFPR. nucci@ufpr.br
} 


\section{ABSTRACT}

The human occupation of landscapes usually despises the benefits that nature can provide, frequently substituting this benefits for created services based in technology resources, with elevated energy consuming. Landscapes with high technology and energetic dependence to its maintenance, with low capacity of auto regulation, poor utilization of nature's functions show high hemeroby. Identifying hemeroby is a technique which makes possible a reflection about types and intensity of anthopogenic landscape's transformations. This research presents the important background and elementary studies on hemeroby, it suggests hemeroby evaluation in urban landscapes criteria and in more detailed scales, applying these suggestions to the district of Pici (Fortaleza - CE - Brazil).

Key-words: Hemeroby, Landscape planning, district of Pici

\section{INTRODUÇÃO}

As interações dinâmicas e na maioria das vezes contraditórias entre a sociedade e a natureza concorrem para o comprometimento das "funções da natureza" (DE GROOT, 1992), tão necessárias a própria sobrevivência humana e para a manutenção de outros valores como os sentimentais, éticos, valores relacionados com a recreação, educacionais, científicos e utilitaristas.

O argumento "sobrevivência" indica que o funcionamento contínuo dos processos naturais é essencial para a existência humana na Terra, e que a alteração desses processos provoca conseqüências negativas para a satisfação das necessidades e ao fornecimento de serviços básicos para a sobrevivência e saúde humana e ambiental.

Apesar de sua importância, os ecossistemas naturais, até bem pouco tempo atrás, foram considerados como áreas improdutivas nas quais benefícios só poderiam ser alcançados se houvesse uma conversão para outros usos. Como resultado, muitas áreas naturais foram e ainda são alteradas para servir a outros propósitos pelo simples motivo de que seus valores para a sociedade não podem ser adequadamente demonstrados. 
Todavia, a avaliação da capacidade dos processos e componentes naturais de fornecerem benefícios e serviços que satisfaçam, direta ou indiretamente, às necessidades humanas (fisiológicas e psicológicas), vem sendo utilizada como uma das estratégias do "Planejamento da Paisagem" (BfN, 2002; HAAREN et al., 2008), o que enfatiza a importância ecológica e sócio-econômica dos ecossistemas naturais.

A valorização do uso das funções da natureza no planejamento da paisagem tem por objetivo, entre outros, o de diminuir a dependência da sociedade por uma manutenção intensiva e dispendiosa, procurando resguardar as paisagens com capacidade de auto-regeneração, respeitando-se o seu arranjo natural e evitando-se as intervenções humanas que requerem um desnecessário e demasiado gasto de energia (SPIRN, 1995; HOUGH, 1995; BETTINI, 1998). Em outras palavras, procura-se planejar e projetar com a natureza e não contra a natureza (McHARG, 1971).

HOUGH (1995) afirma que a vida urbana separada dos processos naturais é destrutiva, e que se deveria procurar criar novas paisagens que gerem modos de vida saudáveis e que não se limitem a remediar os males da cidade, principalmente com base em uma crença na tecnologia; afirma, também, que está surgindo uma consciência de que os processos naturais e os assuntos humanos são questões inseparáveis.

Um termo capaz de sintetizar essas questões é "hemerobia" (JALAS, 1955 apud TROPPMAIR, 1989), que pode ser entendido como a totalidade de alterações nas paisagens, classificadas, assim, de acordo com graus de naturalidade (SUKOPP, 1972), bem como o grau de dependência tecnológica e energética para a manutenção das paisagens (HABER, 1990).

Contudo, o termo hemerobia vem sendo utilizado muito mais com o objetivo de apontar o grau de alterações antropogênicas nas paisagens do que apontar o grau de dependência tecnológica e energética. Além disso, a maioria dos autores ignora o interior das paisagens urbanizadas, propondo análises em escalas pequenas e impróprias para as áreas altamente urbanizadas. 
O trabalho apresenta o estado da arte do uso do termo hemerobia e sugere critérios para a avaliação da hemerobia em paisagens urbanizadas e em escalas maiores das comumente propostas.

Para a verificação da eficácia dos critérios sugeridos foram escolhidas as paisagens que compõem o bairro do Pici (Fortaleza-CE). O bairro do Pici foi escolhido como área teste por apresentar diferentes paisagens, como as do campus da Universidade Federal do Ceará (UFC), da Companhia de água e esgoto do Ceará (CAGECE), importantes avenidas do sistema de transporte do município, áreas residenciais de diferentes classes sociais e centros de comércio próximos. A área também se mostrou a mais conveniente para o trabalho de campo já que foi o local de estágio de conclusão de curso realizado por um dos autores no segundo semestre do ano de 2009, junto ao departamento de Geografia da UFC.(Figura 1).

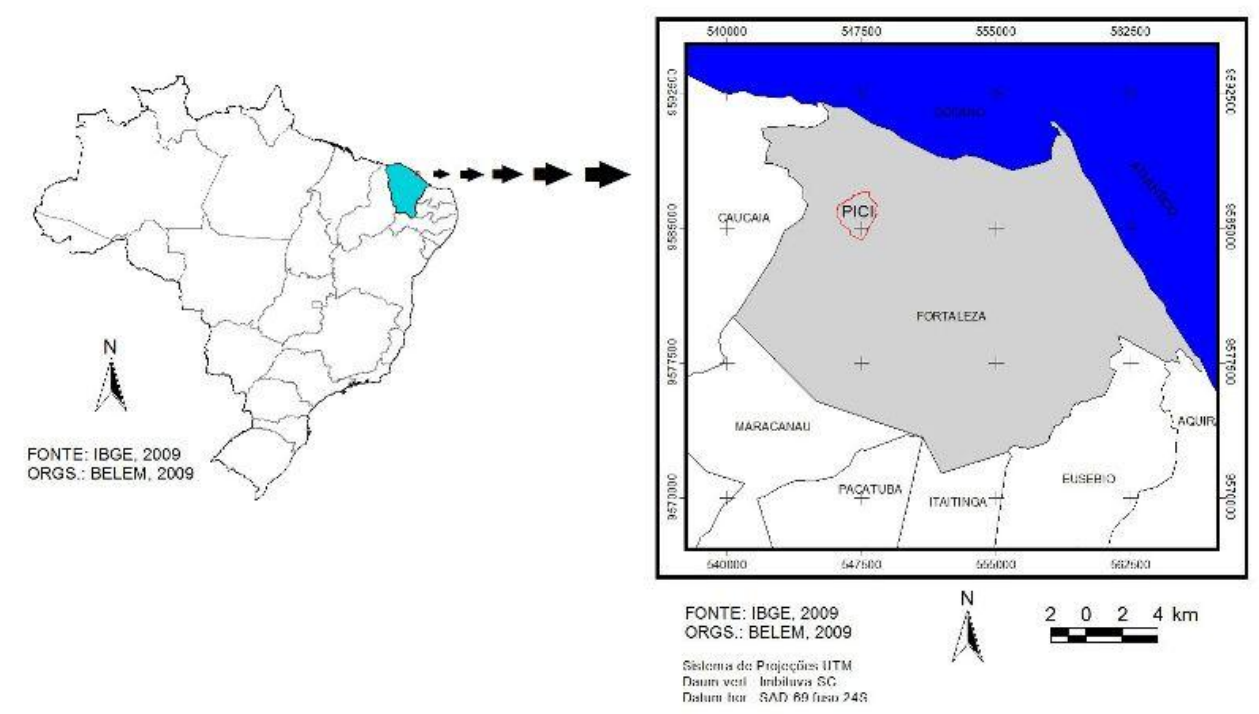

Figura 1 - Localização da área teste: bairro Pici em Fortaleza-CE. 


\section{REVISÃO BIBLIOGRÁFICA}

As transformações realizadas pelos seres humanos na paisagem são necessárias, pois a sobrevivência das espécies depende das trocas de energia, matéria e informação entre o meio e os seres vivos.

Porém, os limites que o meio impõe ao ser humano são menosprezados quando dessas transformações; o homem trata a natureza como produto que deve ser explorado e subordinado aos seus interesses apenas como elemento inserido no sistema econômico. (FÁVERO, et al., 2008)

Mateo Rodrigues et al. (2007) afirmam que o ser humano modifica a paisagem, mas não modifica o funcionamento das leis físicas, apenas muda sua condição de manifestar-se.

Sendo assim, caberia então respeitar determinados limites da paisagem para poder transformar sem afetar totalmente suas funções ecológicas e a capacidade de se auto-renovar. O conhecimento sobre as estruturas e processos da paisagem serve não apenas a exploração econômica, mas também para compreender a velocidade e intensidade em que a sociedade pode realizar tais transformações para seu próprio consumo (RIBEIRO, 1985).

Portanto, torna-se imprescindível um planejamento que considere as potencialidades da natureza, ou seja, seus limites para o uso e suas possibilidades de fornecimento de recursos aos seres humanos que, portanto, considere as funções da natureza na transformação e ocupação das paisagens.

As funções da natureza podem ser classificadas, segundo Van der Maarel e Dauvellier (1978 apud DE GROOT, 1992), Braat et al. (1979 apud DE GROOT, 1992) e De Groot (2006), da seguinte forma:

Funções de Regulação: relata a capacidade dos ecossistemas naturais e seminaturais em regular os processos ecológicos essenciais e 
sistemas de suporte da vida, contribuindo para manutenção da saúde ambiental por fornecer ar, água e solo de boa qualidade. Exemplos: cobertura vegetal contribuindo na proteção do solo, na regulação do escoamento superficial, prevenção contra as enchentes; a vegetação também pode executar um importante papel nas áreas de mananciais ao proteger as nascentes de rios que alimentam os reservatórios de uma região; os corpos hídricos, juntamente com a vegetação, influenciam no clima da região, constituindo zonas de conforto térmico, etc.

Funções de Suporte: fornecimento de espaço, substrato ou meio para atividades humanas tais como habitação, cultivo e recreação. Exemplos: trilhas em Unidades de Conservação que proporcionam a possibilidade de caminhada em contato direto com a natureza, criação de peixes em lagoas e em represas, possibilidade de vários outros tipos de recreação (piquenique, uso de playground, pesca, etc.); áreas que fornecem suporte para a moradia, para a infra-estrutura, para o turismo, para pesquisa, etc.; a vegetação fornece suporte para a vida de inúmeras espécies.

Funções de Produção: a natureza fornece muitos recursos, para a alimentação e matéria-prima para a indústria, recursos energéticos e materiais genéticos. Exemplos: fornecimento de água para várias finalidades, produção de madeira (reflorestamento), de mel, de mudas para reflorestamento e de porta-sementes, recursos medicinais (plantas), ornamentais, etc.

Funções de Informação: ecossistemas naturais contribuem para a saúde mental, fornecendo oportunidades de reflexão, enriquecimento espiritual, desenvolvimento cognitivo e experiências estéticas. Exemplos: belas paisagens naturais servindo de inspiração para quadros, poesia, música; locais calmos para meditação com luz solar filtrada pela vegetação, sons da natureza, etc.

Para se garantir e tirar o maior proveito das funções da natureza é preciso considerar as transformações causadas pelos seres humanos na 
paisagem; se essas transformações estão afastando ou aproximando a paisagem de um funcionamento mais próximo do funcionamento da natureza.

Fávero et al., (2004) afirmam que dentre os conceitos que buscam a avaliação e acompanhamento das mudanças no uso e cobertura da terra, com base em uma constatação dos diferentes graus de modificações, está o de hemerobia.

Jalas (1955 apud TROPPMAIR, 1989) é o propositor do termo "Hemerobia" e atribui ao mesmo o significado de "dominação e/ou alteração das paisagens" assim institui quatro graus hemerobióticos, do mais preservado ao mais antropizado: a-hemerobiótico; oligo-hemerobiótico; mesohemerobiótico; eu-hemerobótico.

Mateo Rodrigues, et al. (2007) apresentam, no quadro 1, uma proposta de classificação das paisagens com utilização do termo hemerobia, semelhante a proposição de Jalas (op. cit.).

O conceito de hemerobia utilizado por Mateo Rodrigues et al. (2007) é entendido como o grau de "mudança e intensidade de modificação" (Quadro 1) da paisagem, considerando as paisagens naturais e semi-naturais como não modificadas ou levemente modificadas. Porém, torna-se muito difícil diagnosticar o grau de modificação de uma paisagem, já que por ser dinâmica, está sempre se modificando e tentando alcançar um teórico clímax, ou seja, um nível máximo de desenvolvimento de acordo com as condições limitantes do meio. No caso da exploração florestal, exemplo citado pelos autores, a paisagem está em constante modificação devido à retirada e reposição de espécies vegetais, portanto, por essa forma de conceituar a hemerobia, não poderia ser colocada como levemente modificada. Uma vegetação, que se apresenta com um avançado grau de desenvolvimento (fases finais da sucessão ecológica) não aponta, necessariamente, para uma baixa intensidade de modificação, já que poderia ter sido explorada, cortada e com o tempo se desenvolveu até aparentar-se como uma vegetação próxima da formação original. 
Quadro 1. Classificação sintética das paisagens antropogênicas.

\begin{tabular}{|c|c|c|c|c|}
\hline Categorias & $\begin{array}{l}\text { Classes } \\
\text { (formas da } \\
\text { atividade } \\
\text { humana) } \\
\end{array}$ & $\begin{array}{c}\text { Tipos } \\
\text { (utilização e } \\
\text { ocupação) }\end{array}$ & $\begin{array}{c}\text { Mudanças e } \\
\text { intensidade da } \\
\text { modificação } \\
\text { (hemerobia) }\end{array}$ & $\begin{array}{c}\text { Componentes } \\
\text { naturais } \\
\text { afetados pela } \\
\text { modificação }\end{array}$ \\
\hline \multirow{2}{*}{$\begin{array}{c}\text { Naturais e } \\
\text { Semi-Naturais }\end{array}$} & Áreas Naturais & $\begin{array}{l}\text { Áreas naturais } \\
\text { sem uso } \\
\text { funcional }\end{array}$ & $\begin{array}{c}\text { Não modificadas } \\
\text { ou levemente } \\
\text { modificadas }\end{array}$ & $\begin{array}{l}\text { Composição da } \\
\text { atmosfera }\end{array}$ \\
\hline & $\begin{array}{c}\text { Exploração } \\
\text { Florestal }\end{array}$ & $\begin{array}{c}\text { Reservas, } \\
\text { parques e } \\
\text { diversos tipos de } \\
\text { áreas protegidas }\end{array}$ & $\begin{array}{l}\text { Levemente } \\
\text { modificadas }\end{array}$ & $\begin{array}{l}\text { Cobertura } \\
\text { vegetal e mundo } \\
\text { animal }\end{array}$ \\
\hline \multirow{4}{*}{ Antropo-naturais } & Turística & $\begin{array}{c}\text { Parques } \\
\text { recreativos } \\
\text { Zonas turísticas } \\
\end{array}$ & $\begin{array}{l}\text { Modificações } \\
\text { leve a moderada }\end{array}$ & \multirow[b]{2}{*}{$\begin{array}{l}\text { Microrrelevo e } \\
\text { microclima }\end{array}$} \\
\hline & Pastoril & $\begin{array}{l}\text { Pastos naturais } \\
\text { Pastos } \\
\text { herbáceos } \\
\text { arbustivo } \\
\text { Pastos artificiais } \\
\text { (melhorados) }\end{array}$ & $\begin{array}{l}\text { Modificação } \\
\text { moderada a } \\
\text { forte }\end{array}$ & \\
\hline & \multirow[t]{2}{*}{ Agrícola } & $\begin{array}{l}\text { Plantações } \\
\text { arbóreas } \\
\text { perenes } \\
\text { Campos e focos } \\
\text { agrícolas de } \\
\text { subsistência }\end{array}$ & $\begin{array}{l}\text { Modificação } \\
\text { forte a muito } \\
\text { forte }\end{array}$ & \multirow[t]{2}{*}{$\begin{array}{l}\text { Solos águas } \\
\text { superficiais e } \\
\text { subterrâneas }\end{array}$} \\
\hline & & $\begin{array}{l}\text { Plantações } \\
\text { agrícolas } \\
\text { irrigadas ou } \\
\text { dissecadas } \\
\end{array}$ & $\begin{array}{c}\text { Modificação } \\
\text { forte e } \\
\text { transformação } \\
\text { artificial } \\
\end{array}$ & \\
\hline \multirow{3}{*}{ Antrópicas } & Urbana & $\begin{array}{c}\text { Cidades } \\
\text { intermediárias e } \\
\text { grandes } \\
\text { Povoados e } \\
\text { Vilas rurais }\end{array}$ & \multirow{3}{*}{$\begin{array}{c}\text { Artificialização e } \\
\text { transformação } \\
\text { antropogênica }\end{array}$} & \multirow{3}{*}{$\begin{array}{l}\text { Estrutura } \\
\text { geológica, } \\
\text { mesorelevo e } \\
\text { mesoclima }\end{array}$} \\
\hline & Minero-Industrial & $\begin{array}{c}\text { Áreas de } \\
\text { exploração de } \\
\text { jazidas minerais } \\
\text { Áreas } \\
\text { industriais, de } \\
\text { armazéns e } \\
\text { portos }\end{array}$ & & \\
\hline & $\begin{array}{l}\text { Exploração de } \\
\text { Recursos } \\
\text { hídricos }\end{array}$ & $\begin{array}{c}\text { Reservatórios } \\
\text { pequenos e } \\
\text { canais } \\
\text { Grandes } \\
\text { Barragens }\end{array}$ & & \\
\hline
\end{tabular}

Fonte: Mateo Rofrigues, et al. (2007, p. 165). 
Outro aspecto que poderia ser explorado com base na proposição de Mateo Rodrigues et al (2007) é o da categoria "antrópica", classe "urbana" que os autores classificam com o grau de hemerobia "artificialização e transformação antropogênica". Obviamente que a paisagem urbanizada é uma dos exemplos de maiores transformações ocasionadas pelo ser humano nas paisagens e que, na maioria dos casos, a paisagem urbanizada é considerada como um "ecossistema heterotrófico" (ODUM, 1983), todavia, podem ser encontradas dentro do meio urbano, paisagens que ainda não foram muito alteradas ou paisagens que tiveram suas características modificadas para que se aproximassem do funcionamento da natureza. Nesse sentido, também é preciso valorizar os estudos das paisagens urbanizadas em escalas mais detalhadas para que se possa, por exemplo, delimitar os biótopos urbanos, ou seja, áreas que fornecem possibilidades de desenvolvimento da fauna e da flora, mesmo em áreas fortemente urbanizadas (BEDÊ et al., 1997; BERLIM, 2003).

Não existem limites escalares para se delimitar a hemerobia das paisagens. Troppmair (1983 a e b), por exemplo, aplicou o conceito de hemerobia segundo Jalas (op. cit.), em escala pequena (1:2.000.000) para 0 Estado de São Paulo, enquanto que Fávero et al. (2008) aplicaram o mesmo conceito para uma bacia hidrográfica em escala da ordem de 1:250.000; Fávero et al. (2004) classificaram os graus de hemerobia de uma Unidade de Conservação da Natureza em escala de 1:50.000 e Kröker et al. (2005) e Kröker (2008) aplicaram o conceito em bairros urbanizados em escalas próximas a de 1:10.000.

O conceito de hemerobia desenvolvido por Sukopp (1972) está mais adaptado para o uso em escalas maiores e também em paisagens urbanizadas. Sukopp (1972) define hemerobia como a totalidade dos efeitos do ser humano nos ecossistemas/paisagens, sendo esses efeitos voluntários ou não (Quadro 2). 
Quadro 2. Graus de naturalidade e de estado hemerobiótico (Sukopp, 1972).

\begin{tabular}{|c|c|c|c|c|c|c|}
\hline Naturalidade & $\begin{array}{c}\text { Estado } \\
\text { hemerobiótico } \\
\text { (hemero- } \\
\text { cultivado) }\end{array}$ & $\begin{array}{c}\text { Mudanças } \\
\text { no } \\
\text { substrato }\end{array}$ & $\begin{array}{c}\text { Mudanças } \\
\text { na } \\
\text { estrutura }\end{array}$ & $\begin{array}{c}\text { Mudanças } \\
\text { na } \\
\text { composição } \\
\text { florística }\end{array}$ & $\begin{array}{c}\text { Perda de } \\
\text { espécies } \\
\text { naturais } \\
\text { (\%) }\end{array}$ & $\begin{array}{c}\text { Ganho } \\
\text { de } \\
\text { novas } \\
\text { espécies } \\
\text { (\%) }\end{array}$ \\
\hline Natural & A-hemerobiótico & não & não & não & 0 & 0 \\
\hline Quase natural & $\begin{array}{c}\text { Oligo- } \\
\text { hemerobiótico }\end{array}$ & Pouco & Não & $\begin{array}{c}\text { Maioria das } \\
\text { espécies } \\
\text { espontâneas }\end{array}$ & $<1$ & 5 \\
\hline $\begin{array}{c}\text { Semi (agro) } \\
\text { natural }\end{array}$ & $\begin{array}{c}\text { Meso- } \\
\text { hemerobiótico }\end{array}$ & $\begin{array}{c}\text { Pouco } \\
\text { Superficial }\end{array}$ & $\begin{array}{c}\text { Outra vida } \\
\text { dominante }\end{array}$ & $\begin{array}{c}\text { Maioria das } \\
\text { espécies } \\
\text { espontâneas }\end{array}$ & $1-5$ & $5-12$ \\
\hline Quase Natural & $\begin{array}{c}\text { Eu- } \\
\text { hemerobiótico }\end{array}$ & $\begin{array}{c}\text { Moderado } \\
\text { e drástico }\end{array}$ & $\begin{array}{c}\text { Dominam } \\
\text { os cultivos }\end{array}$ & $\begin{array}{c}\text { Poucas } \\
\text { espécies } \\
\text { espontâneas }\end{array}$ & 6 & $13-20$ \\
\hline Poli- & $\begin{array}{c}\text { Substrato } \\
\text { artificial, } \\
\text { hudança } \\
\text { drástica }\end{array}$ & $\begin{array}{c}\text { Aberto- } \\
\text { efêmero }\end{array}$ & $\begin{array}{c}\text { Nenhuma e } \\
\text { poucas } \\
\text { espécies }\end{array}$ & 2 & $21-80$ \\
\hline Merobictico & $\begin{array}{c}\text { Meta- } \\
\text { hemerobiótico }\end{array}$ & $\begin{array}{c}\text { Substrato } \\
\text { artificial }\end{array}$ & - & - & - & - \\
\hline
\end{tabular}

Na proposição de Sukopp (1972), uma das questões que causam certo desconforto é a classificação segundo "graus de naturalidade"; as paisagens são classificadas desde "natural" até "cultural". A crítica surge ao se considerar uma paisagem como natural. Considerando-se que o ser humano influencia direta ou indiretamente todas as paisagens da Terra, poder-se-ia dizer que sempre há natureza nas paisagens culturais e sempre há cultura nas paisagens naturais. Sendo assim, torna-se impossível classificar as paisagens em naturais ou culturais.

Apesar dos problemas apontados, vários autores entendem a hemerobia da mesma forma proposta por Sukopp (1972). Kowarik (1999 apud BENTRUP et al., 2002) utiliza o termo hemerobia como o desvio de naturalidade causado pelo ser humano de acordo com o tipo de uso da terra. Segundo Brentrup et al. (2002), aplica-se o termo hemerobia para "to investigate the level of naturalness of specific landscapes and ecosystem"; os autores propõem onze classes de hemerobia pautadas no uso da terra e seus impactos nos ciclos de vida e justificam que o conceito hemerobia não se baseia em um único 
indicador mas, pelo contrário, possibilita uma análise integrada da paisagem. Dueñas (2004) também valoriza o conceito de hemerobia em estudos da paisagem como um todo de maneira qualitativa e cita os trabalhos de Steinhardt et al.(1999) em que o termo é usado para fazer "referencia al impacto de las intervenciones humanas en los ecosistemas (medida de la influencia antrópica)".

Monteiro (1978), escrevendo sobre a ação humana nas paisagens, apresenta o termo "Derivações Antropogênicas", e explica que os efeitos das alterações do ser humano na paisagem podem ser benéficos ou não, para contrapor à noção de que o ser humano sempre provocaria impactos negativos ao alterar as paisagens. Nesse caso, o ser humano poderia ter por objetivo a recuperação da naturalidade de uma paisagem quando executa, por exemplo, um plano de recuperação de áreas degradadas por reposição florestal.

Diferentemente dos autores anteriores, ODUM (1983) propõe uma classificação dos ecossistemas baseada na energia. Distingue, assim, quatro classes básicas de ecossistemas:

1. Ecossistemas naturais que dependem da energia solar, sem outros subsídios; exemplos: oceanos abertos, florestas de altitudes;

2. Ecossistemas naturais que dependem da energia solar, com subsídios de outras fontes naturais de energia; exemplos: estuário de marés, algumas florestas úmidas;

3. Ecossistemas que dependem da energia solar, com subsídios antropogênicos; exemplos: agricultura, aquacultura; e

4. Sistemas urbano-industriais, movidos a combustível (combustíveis fósseis ou outros combustíveis orgânicos ou nucleares são as fontes de energia); exemplos: cidades, bairros residenciais, zonas industriais. 
Um horizonte mais nítido surge com Haber (1990) ao apresentar uma proposta de classificação com base na dependência tecnológica dos sistemas. Não faz menção ao termo hemerobia e propõe os termos Bio-ecossistemas e Tecno-ecossistemas. Os bio-ecossistemas são divididos em quatro tipos: ecossistemas naturais (sem influência humana direta e capaz de autoregulação), ecossistemas próximos de naturais (com influência humana, mas similar ao anterior e capaz de auto-regulação), ecossistemas semi-naturais (resultantes do uso humano sobre os tipos anteriores, mas não criados intencionalmente, com capacidade limitada de auto-regulação, requerendo manejo) e ecossistema (biótico) antropogênico (intencionalmente criado e totalmente dependente do controle e manejo humanos). Os tecnoecossistemas são caracterizados pelo domínio de estruturas e processos técnicos, criados intencionalmente pelo homem para atividades industriais, econômicas ou culturais com bio-ecossistemas dispersos em sua malha e no entorno.

Portanto, Haber (1990) classifica os ecossistemas de acordo com a necessidade de uso de tecnologia e energia para a manutenção, ou seja, não aborda a questão segundo graus de naturalidade ou artificialidade e nem por meio de graus de modificação das paisagens quando descreve os tipos de ecossistemas e usos da terra existentes, no corpo da tabela 1 elaborada por ele (HABER, 1990, p. 219). Entretanto, é preciso esclarecer que no título da tabela e no texto, também na página 219, o professor Wolfgang Haber escreve que os ecossistemas foram classificados em ordem decrescente de naturalidade e crescente de artificialidade, o que vinha trazendo confusão para as avaliações que se basearam naquela proposição.

Haber (1990) ainda considera que mesmo nos ecossistemas urbanos (tecno-ecossistemas), por exemplo, pode-se encontrar também bioecossistemas espalhados em sua malha e no entorno, o que fornece um incentivo para as pesquisas em paisagens urbanizadas e em escalas maiores. 
Em acordo com Haber (1990), Mateo Rodrigues (et al, 2007) colocam que nas paisagens antrópicas (tecnogênicas) são alterados os biocomponentes, bem como os elementos estruturais como as formas de relevo e até o embasamento geológico. Em decorrência dessas alterações surgem o que os autores chamam de paisagens reguladas (urbanas, industriais, hídricas), reguladas e mantidas por tecnologias.

Em se tratando de paisagens urbanizadas, pode ser acrescentado, também com a intenção de se avaliar o grau de interferência humana, os dois tipos de paisagens - formal e natural - e suas características, como coloca HOUGH (1995). Para esse autor a paisagem formal apresenta pouca conexão com a dinâmica dos valores naturais, é considerada como uma expressão de esmero, estética e civismo, requerendo muita energia e uso de tecnologia, engenharia e horticultura, com um desenho padrão independentemente do lugar, podendo ser encontrada em qualquer parte; já a paisagem natural representaria a vitalidade dos processos naturais e sociais que, mesmo alterados, atuam na cidade, mas, que apesar disso, é considerada, pela maioria, como terreno baldio abandonado, necessitando de renovação urbana.

Nucci (2008) chama a atenção para o fato de o planejamento estar atrelado somente a medidas de ordem tecnológica desconsiderando os limites físicos da paisagem; para Cavalheiro (2009) a alternativa mais interessante para a urbanização é primeiro ver o que a paisagem pode oferecer no que tange a sua auto-regeneração e depois verificar quais as tecnologias a serem utilizadas.

Neste sentido, o conceito de hemerobia também pode colaborar como uma ferramenta técnico/científica de monitoramento ambiental ( $\mathrm{NUCCl}$ e FÁVERO, 2003). 


\section{PROCEDIMENTOS}

Para a organização dos critérios de avaliação dos graus de hemerobia foram utilizadas diretamente as contribuições de Haber (1990), Hough (1995), Van der Maarel e Dauvellier (1978 apud DE GROOT, 1992), Braat et al. (1979 apud DE GROOT, 1992) e Sukopp (1972).

Houve uma preferência para a utilização do termo "paisagem" no lugar de "ecossistema", já que, segundo Delpoux (1974), o ecossistema, ao contrário da paisagem, não apresenta a dimensão espacial, o que impossibilita a sua delimitação em mapas.

O mapeamento das paisagens do bairro foi realizado na escala 1:10.000. Foram utilizadas imagens retiradas do software Google Earth (Imagens fornecidas pela empresa Digital Globe) do ano de 2007, a base de dados cartográficos (limites territoriais e arruamento) do IBGE (2.000) e do Plano Diretor Participativo de Fortaleza (PDPFor, 2005), utilizando-se o ArcView 3.2. (SIG e cartografia digital), AutoCAD 2002 e Corel Draw 12 (desenho).

As técnicas de cartografia digital foram pautadas na interpretação visual de imagens sem uso de estereoscopia, utilizando-se de ferramentas de vetorização disponibilizadas pelo software. A montagem do Sistema de Informações Geográficas da área (área, quantidade de polígonos, determinação/identificação dos graus de hemerobia) foi feita de acordo com as ferramentas disponíveis no software. Junto ao trabalho de cartografia digital foram utilizadas as técnicas de cartografia temática.

A figura 2 apresenta a chave de classificação dos graus de hemerobia utilizada para a avaliação das paisagens do bairro Pici. 
Figura 2 - Critérios para avaliação relativa da hemerobia da paisagem. Org.: Anderson L. G. Belem e João Carlos Nucci, 2010.

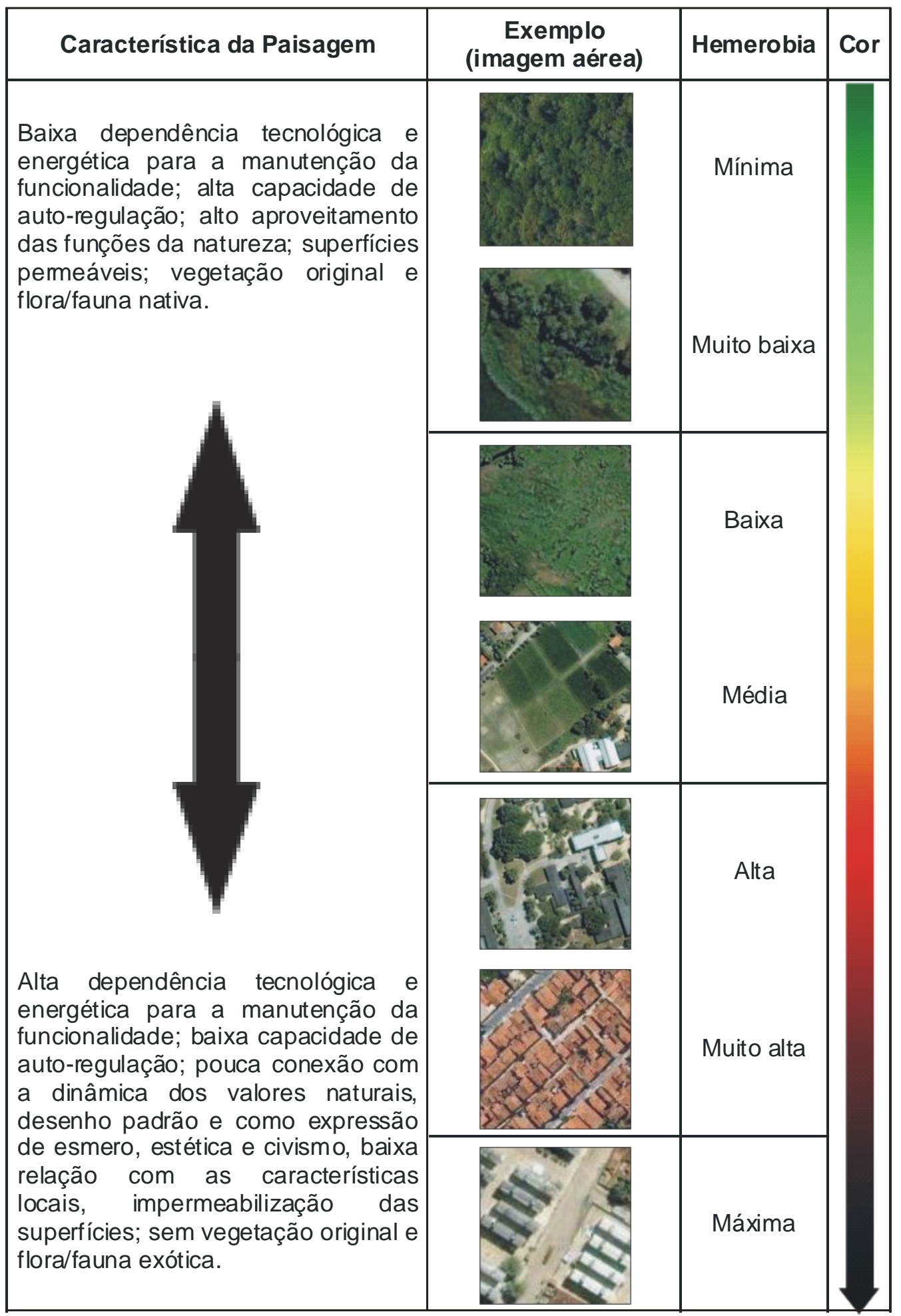


A identificação dos graus de hemerobia (de mínima a máxima) não é absoluta, mas dependente dos tipos de paisagem encontrados na área, ou seja, trata-se de uma avaliação relativa com comparação entre as diferentes paisagens no bairro Pici.

A figura 3 apresenta a carta base utilizada para o mapeamento e avaliação das paisagens.

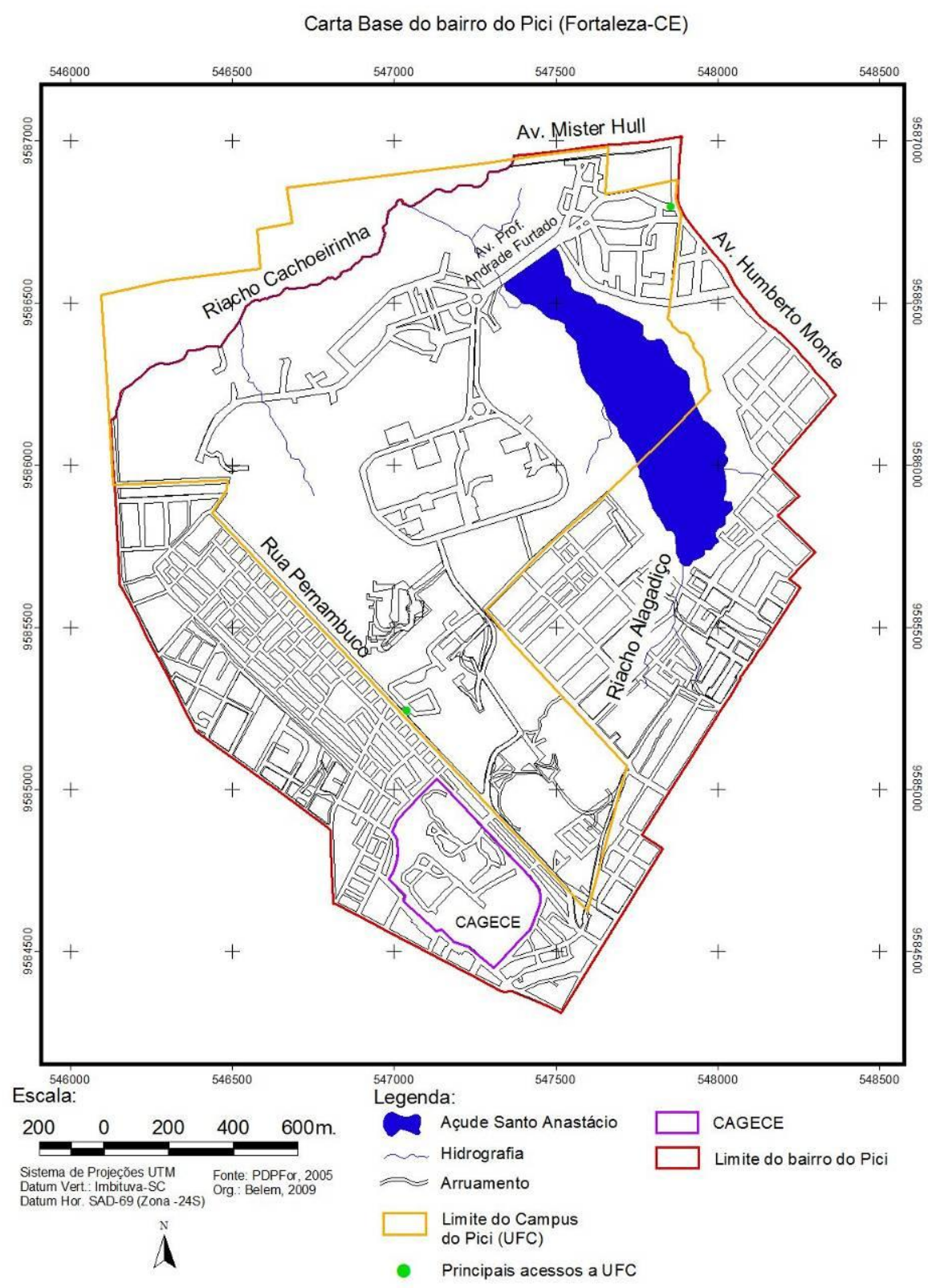

Figura 3. Carta base do bairro do Pici (Fortaleza-CE). 


\section{RESULTADOS E DISCUSSÃO}

Foram encontradas as seguintes classes de hemerobia no bairro do Pici:

I - Paisagem com hemerobia mínima. Caracterizada por vegetação original remanescente. A vegetação segundo Pereira e Silva (2007) é Subcaducifólia de Tabuleiro que se estende por todo o tabuleiro pré-litoraneo do Ceará. Para o IBGE (2004) essa vegetação é designada por Savana-Estépica, caracterizada por apresentar estrato arbóreo e gramíneo-lenhoso, com espécies em sua maioria de porte pequeno, raquíticas, com esgalhamento profuso; boa parte das espécies apresenta alguma adaptação xerofítica como acúleos, espinhos e microfoliação (IBGE, 2004). Já nas margens do açude a vegetação rasteira forma um denso tapete vegetal e as condições hídricas permitem uma vegetação arbórea adensada e de maior porte. Os fragmentos desta categoria encontram-se bem conservados. Os processos ecológicos se mantêm em equilíbrio dinâmico não dependendo da regulação humana para isto, apesar da existência de alguma influência humana na paisagem (Foto 1).

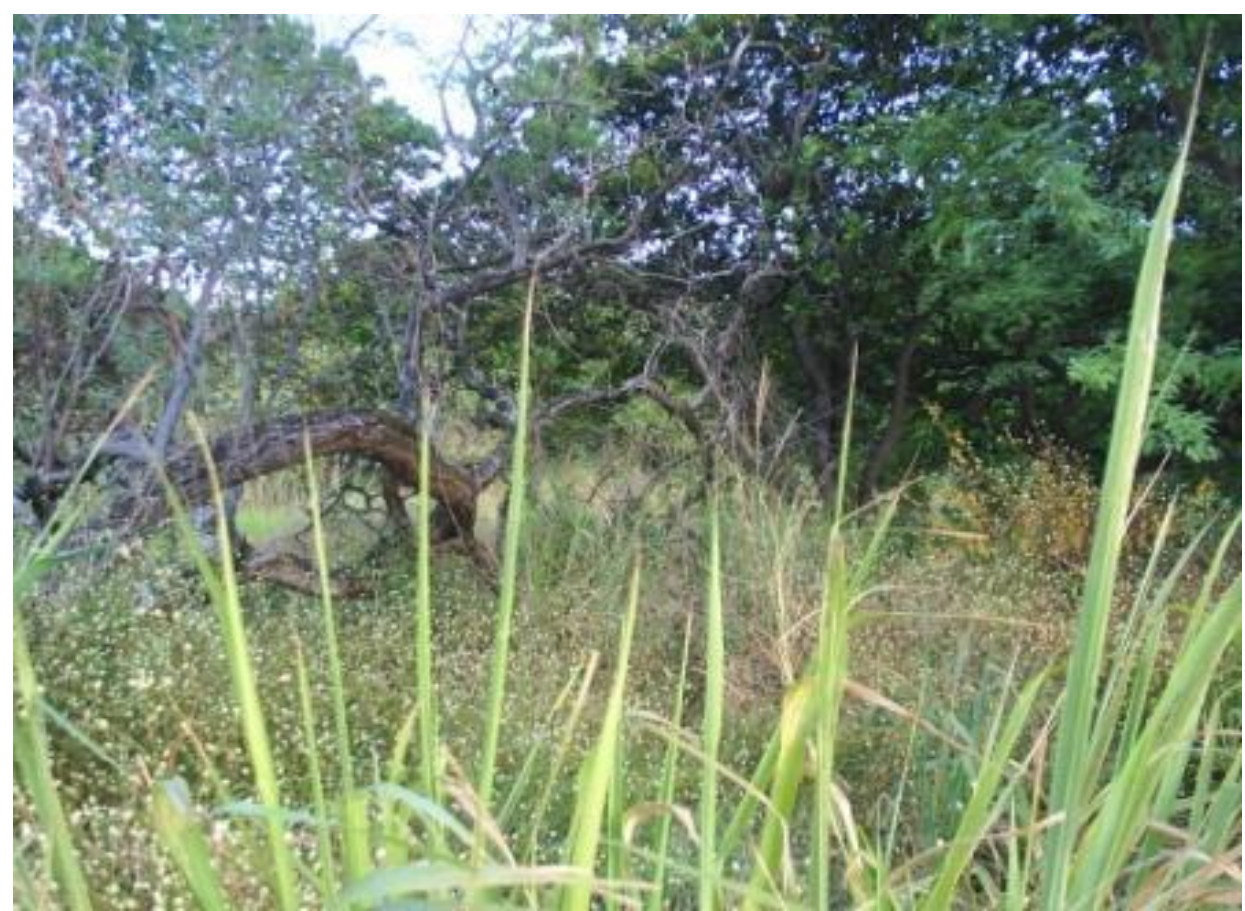

Foto 1. Parte Norte (sentido Norte-Sul) do Campus da UFC, próximo à Av. Prof. Andrade Furtado representando uma paisagem com hemerobia mínima. (Bairro do Pici, Fortaleza, CE). Foto: Anderson L. G. Belem (2009). 
II - Paisagem com hemerobia muito baixa. São áreas modificadas pelo ser humano, predominantemente por ser uma área propícia a ocupação graças a estabilidade fornecida pelo sistema ambiental de Tabuleiros Prélitorâneos, assim como grande parte do território de Fortaleza (SOUZA et al., 2009). Os cursos hídricos se encontram alterados pelo homem por uso inadequado como ligações de esgoto, receptor de lixo doméstico e por alterações por obras de engenharia na organização natural da paisagem. Ocorrem fragmentos espaçados de vegetação nativa e alterada, na forma de bosques e/ou de terrenos abandonados; os indivíduos arbóreos e arbustivos se encontram um pouco espaçados, o que permite o desenvolvimento de espécies herbáceas. Apresenta necessidades tecnológicas para sua manutenção como, por exemplo, o tratamento das águas predominantemente contaminadas ou retirada de sedimentos do açude (Foto 2).

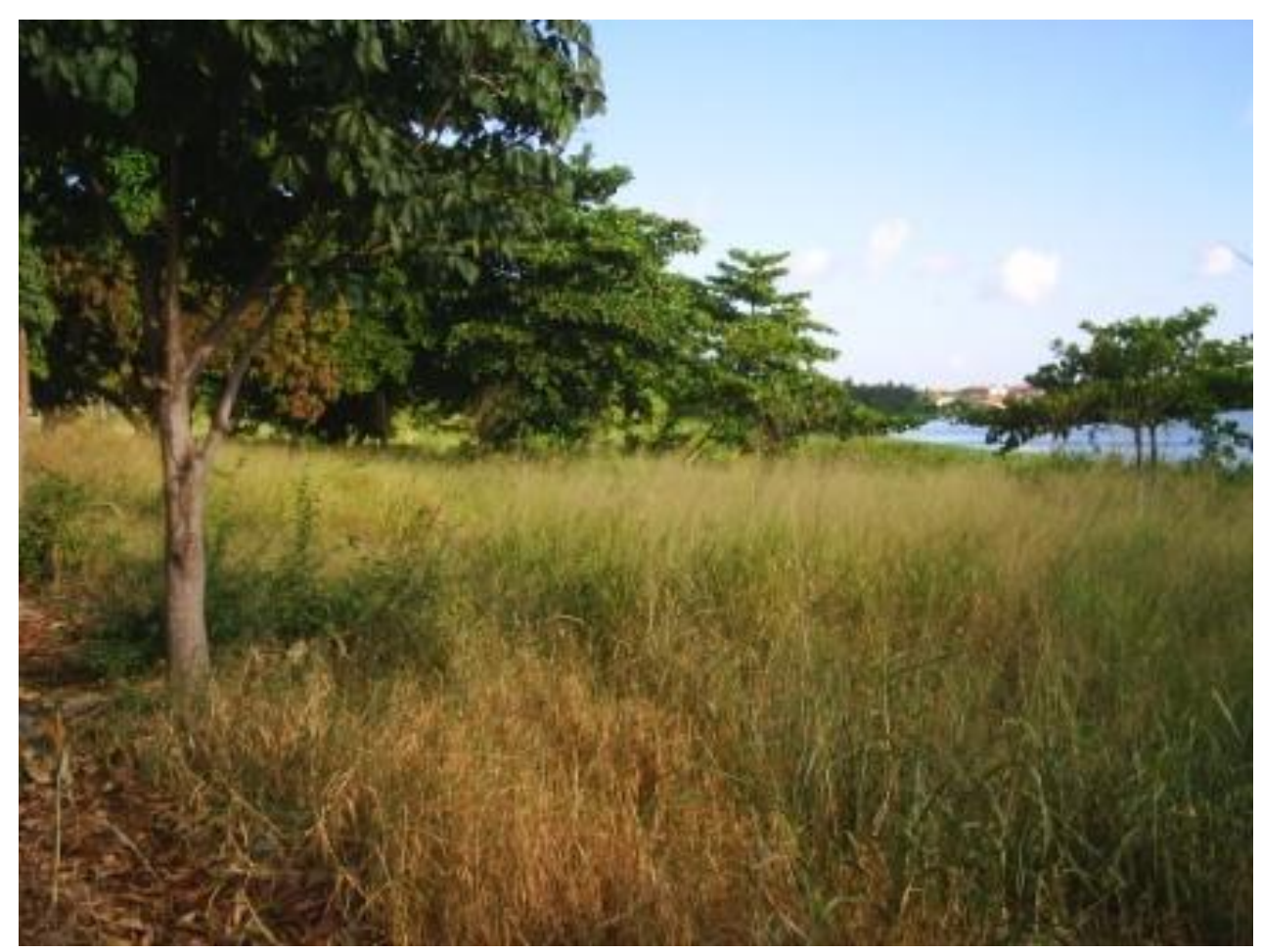

Foto 2. Porção Nordeste do Campus da UFC (sentido NE-SW) árvores espaçadas em uma área de campo com ruderais; ao fundo parte do açude Santo Anastácio (Bairro do Pici, Fortaleza, CE). Foto: Anderson L. G. Belem (2009). 
III - Paisagem com hemerobia baixa. Com o uso antrópico, principalmente a urbanização e uso militar ocorrido na área durante a Segunda Grande Guerra, tais áreas acabaram sendo devastadas, sendo muitas delas abandonadas e outras mantidas com vegetação rasteira por interesses estéticos e de lazer. Atualmente são áreas formadas por vegetação herbácea e ruderal, e em algumas áreas aparecem pequenos arbustos. Os campos podem estar em terrenos baldios entre outros usos ou como clarões entre áreas de mata devastada. As funções ecológicas de tais áreas são consideráveis uma vez que além da existência de biodiversidade, a água tem facilidade de infiltração, o solo não se apresenta compactado e com a presença de espécies vegetais minimizam-se problemas de erosão. Entretanto, a capacidade de auto-regulação aparece limitada pela modificação que já fora causada. Em alguns casos a manutenção constante das áreas (como corte de grama, retirada de árvores e poda constante) não permite uma regeneração natural da área. Assim a dependência tecnológica é maior do que nas duas classes anteriores. Apesar de não serem totalmente elaboradas culturalmente, tais áreas são intencionalmente mantidas (Foto 3).

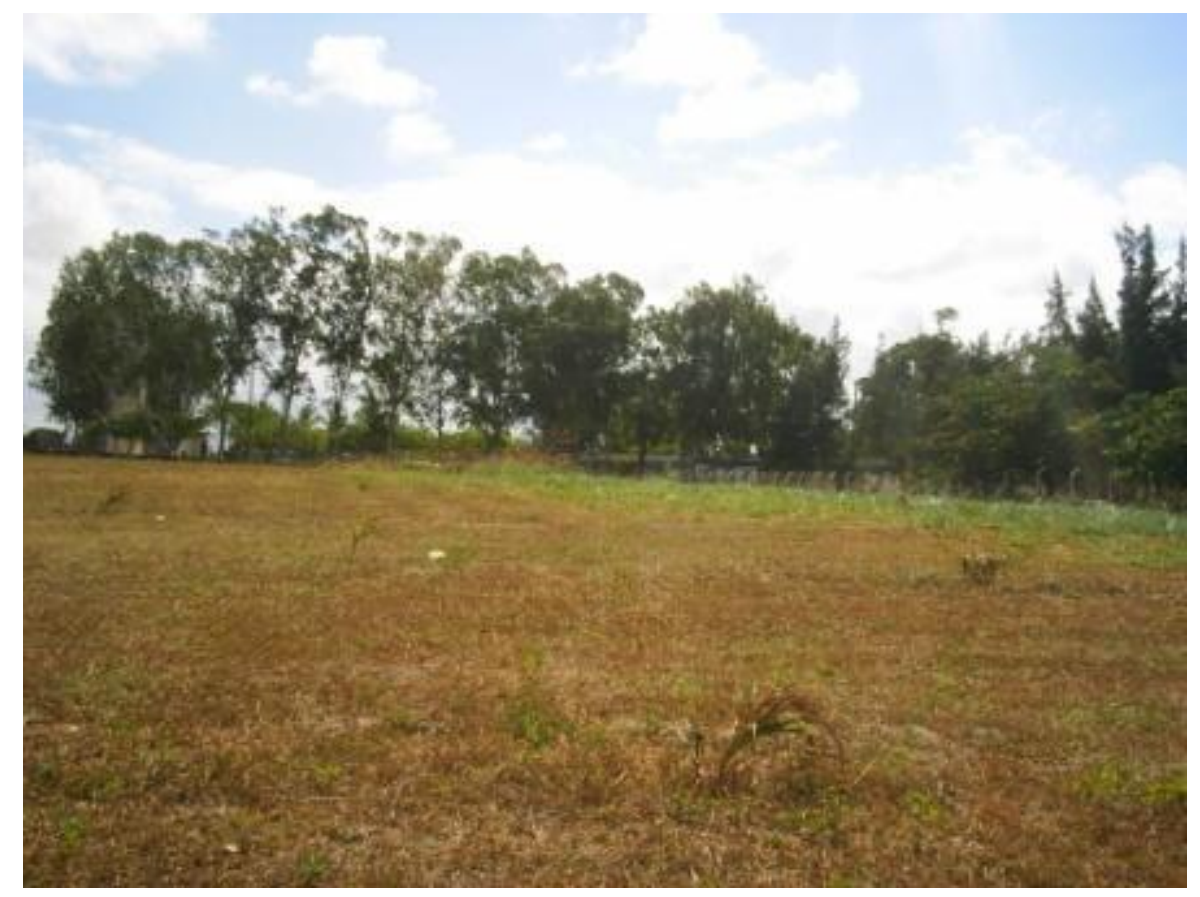

Foto 3. Área ao Sul do Bairro dentro do Campus da UFC (sentido L-W) campos com ruderais dominam a área; árvores limitam o Campus com o restante do bairro (Bairro do Pici, Fortaleza, CE). Foto: Anderson L. G. Belem (2009). 
IV - Paisagem com hemerobia média: as áreas de culturas e as áreas de solos expostos foram classificadas com o mesmo grau de interferência humana; o uso agrícola remexe o solo, introduz espécies exóticas podendo haver a diminuição de nutrientes pelo plantio e colheita constantes, faz usos de fertilizantes e agrotóxicos que contaminam o solo e o lençol freático, provoca erosão e acaba com a reserva de sementes existentes no solo que serve à sucessão natural; as áreas de solos expostos encontram-se prontas para abrigar edificações, com execução de terraplanagem, perda de nutrientes, erosão e modificações no ciclo hidrológico. Há também áreas de solo exposto que estão relacionadas a devastação das matas originais, com o revolvimento do solo, perda de nutrientes e do banco de sementes, ou ainda, compactação do solo o que acarreta o não estabelecimento dos processos de sucessão natural mantendo o solo exposto. A paisagem é intencionalmente criada pelo ser humano e a dependência de tecnologia para manejo é essencial, sem a qual tal paisagem se desestabilizaria até encontrar um novo equilíbrio, no entanto, sua característica estrutural é de vegetação e solo, e não estruturas como edificações e equipamentos construídos tais como gasodutos, estacionamentos, calçamento e avenidas. (Foto 4)

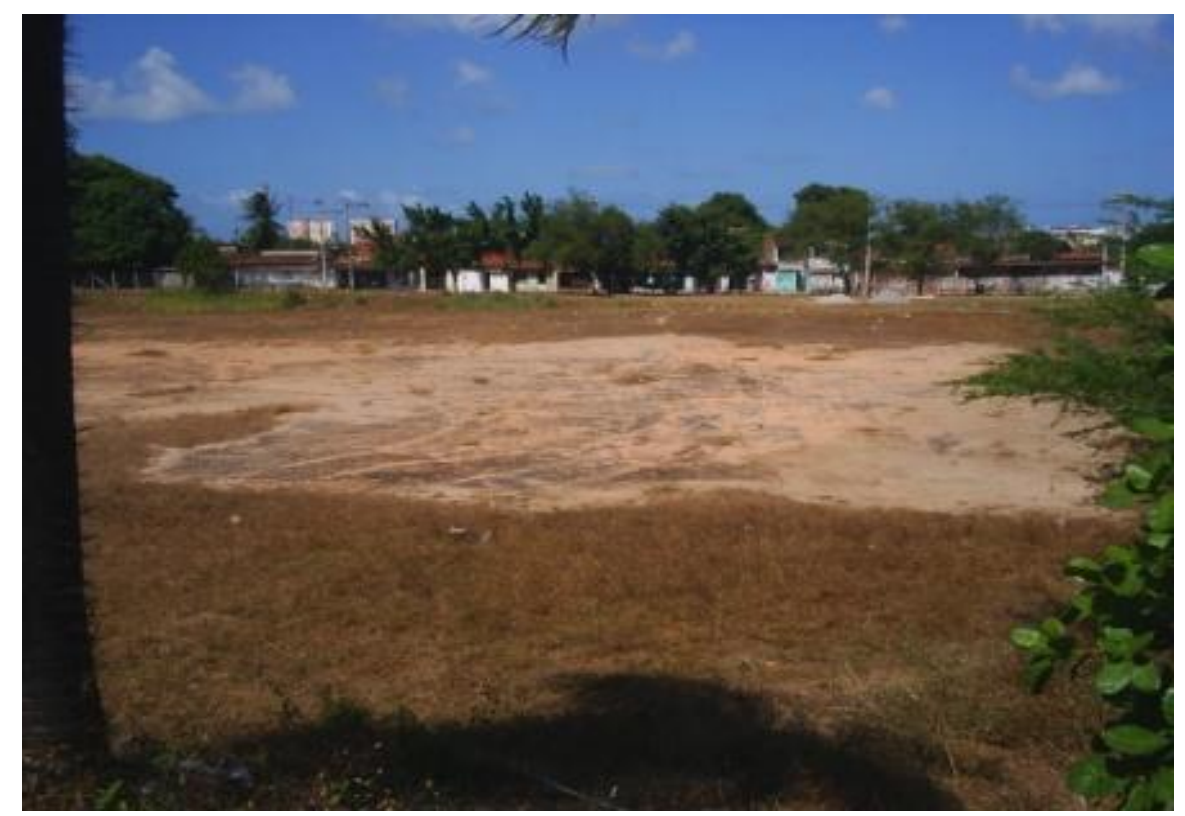

Foto 4. Área Sul do bairro, dentro do Campus do Pici em área de solos exposto (sentido W-L); e ao fundo construções adensadas de pequeno porte (Bairro do Pici, Fortaleza, CE). Foto: Anderson L. G. Belem (2009). 
V - Paisagem com hemerobia alta. Presença de edificações de pequeno porte e contando ainda com áreas de jardins e outras superfícies não impermeabilizadas que criam áreas aglutinadas permeáveis e impermeáveis. A impermeabilização e compactação do solo acarretam prejuízos as funções ecológicas da paisagem e assim uma diminuição da qualidade ambiental. Nesta classe de hemerobia a necessidade de tecnologias para a autoregulação da paisagem surge com o adendo de estruturas criadas pelo ser humano (construções). Apesar da dependência tecnológica e esmero estético a presença de bosques, gramados e o espaçamento entre as edificações favorecem algumas funções naturais referente ao ciclo da água, além de outras como a troca de ar entre as camadas da atmosfera próxima pela presença da vegetação. Isto diminui a intensidade dessa dependência tecnológica em tais áreas podendo ser classificada como fraca, porém mantendo a característica da necessidade de alguma tecnologia para manter o equilíbrio ecológico (Foto $5)$.

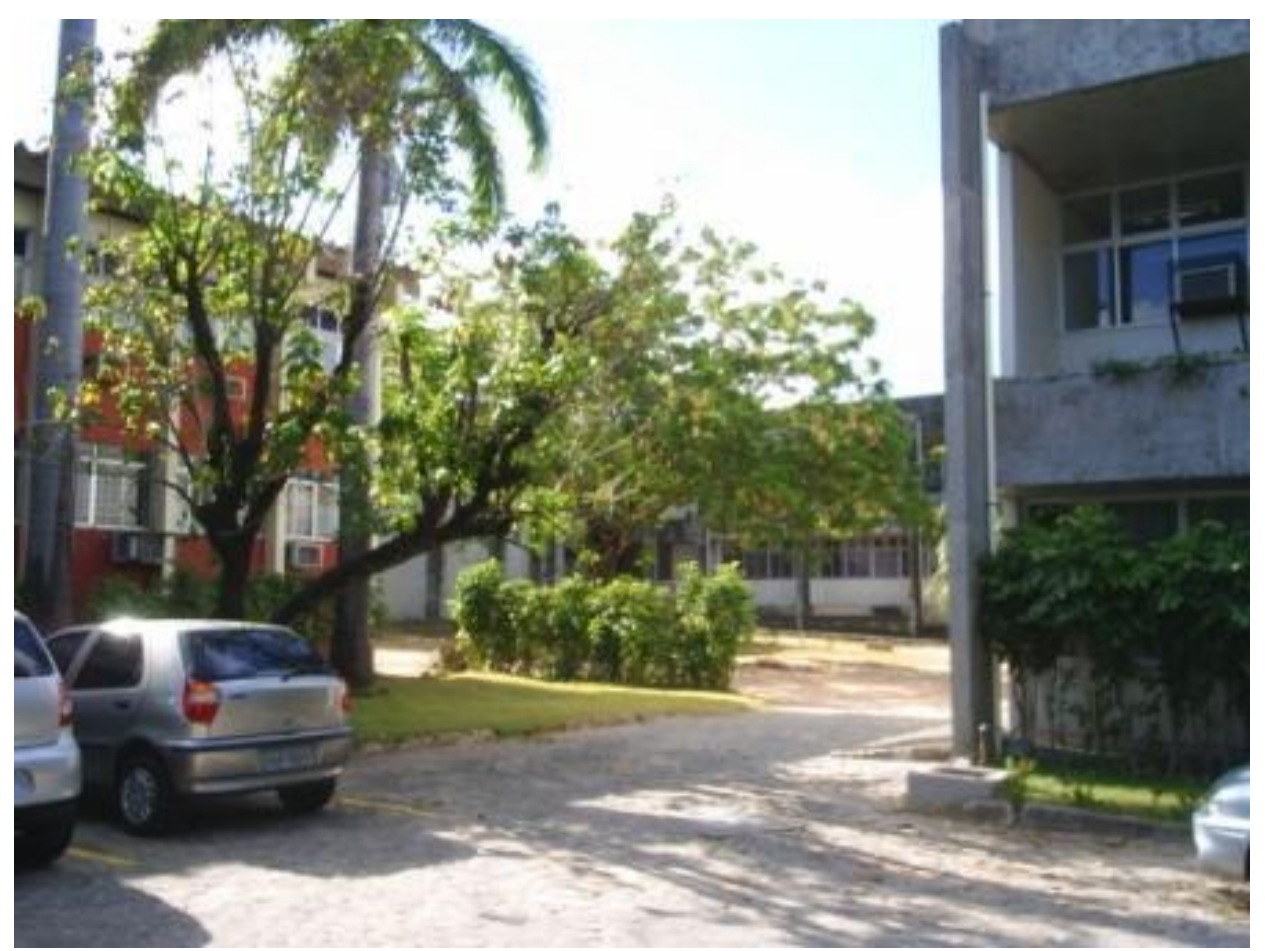

Foto 5. Edificios acadêmicos com dois andares ao centro do bairro (sentido SENW) mostra o espaçamento entre os blocos com presença de vegetação arbórea, herbácea e arbustiva (Bairro do Pici, Fortaleza, CE). Foto: Anderson L. G. Belem (2009). 
VI - Paisagem com hemerobia muito alta. Apresenta característica semelhante às do grau anterior, porém a maior concentração das edificações elimina da paisagem os mosaicos superficiais gerados pelos jardins e alguma arborização. Logo, existem mais áreas impermeabilizadas e edificadas o que potencializa os efeitos negativos da ocupação humana, a concentração por vezes elimina até a arborização de ruas e se junta a falta de espaços livres de edificação acarretando em grandes polígonos de áreas com este grau hemerobiótico. As funções da natureza são desprezadas e a dependência tecnológica e a intensidade de manutenção são altas. Pode-se citar dentre outras necessidades, aumento da rede de galerias fluviais devido falta de espaços livres de edificação não impermeabilizados, tecnologias de limpeza de águas uma vez que o escoamento superficial leva consigo quantidades consideráveis de resíduos químicos das construções, calçadas e asfalto, etc.

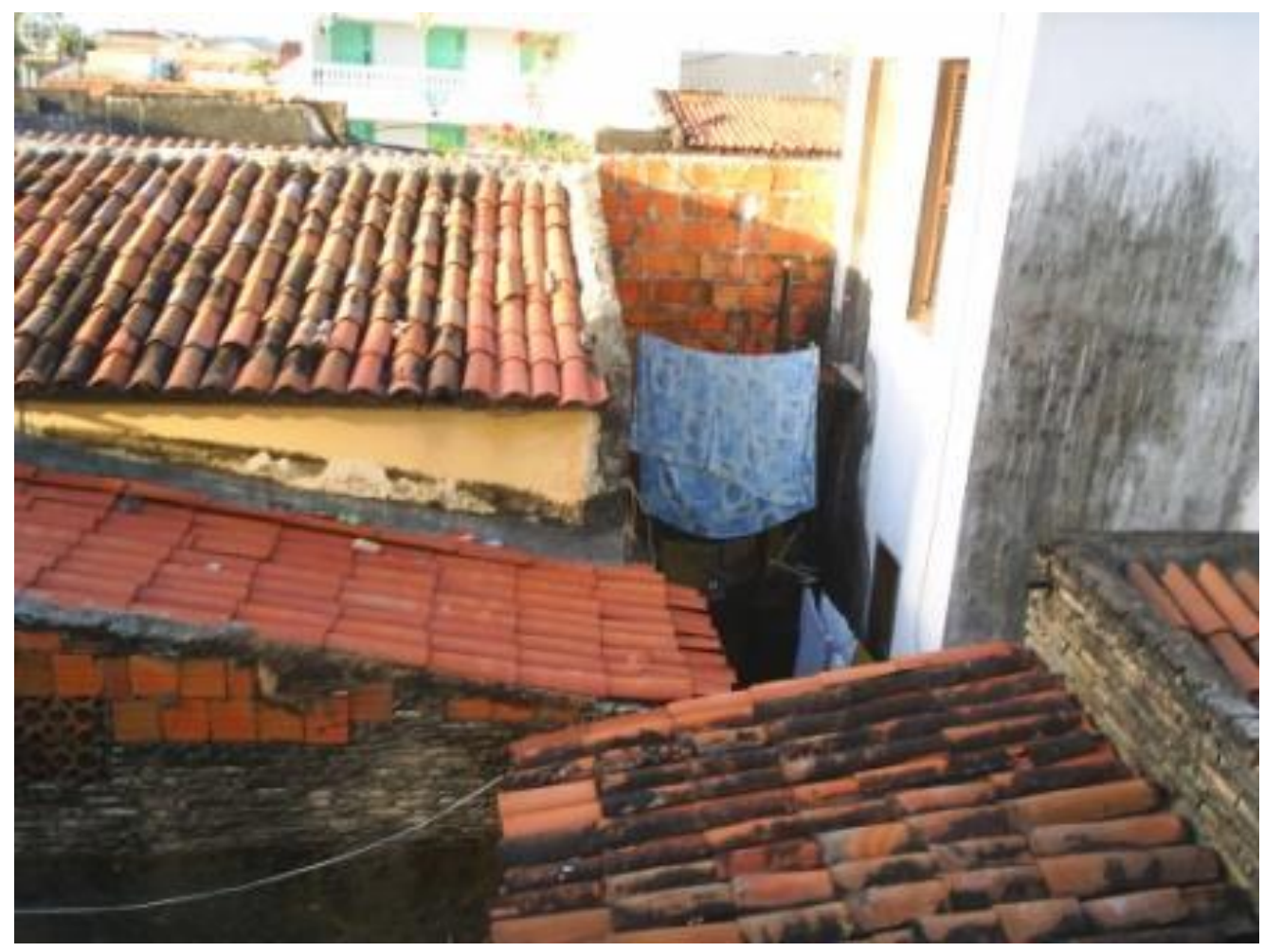

Foto 6. Área do interior de uma residência no bairro do Pici, localizada a Sudeste (sentido da foto N-S), mostra a densidade das edificações distribuídas pelo quarteirão quase sem presença de vegetação (Bairro do Pici, Fortaleza, CE). Foto: Anderson L. G. Belem (2009). 
VII - Paisagem com hemerobia máxima. A impermeabilização atinge os maiores graus devido ao porte e a área ocupada pelas edificações, associados a inexistência de cobertura vegetal, o que intensifica as alterações no ciclo hidrológico, contribuindo também para outros problemas ambientais urbanos. A particularidade desta categoria associa-se ainda a modificação do microclima, pois por vezes a altura dos edifícios ou a grande área que ocupam modificam a dinâmica atmosférica natural. A dependência de uma manutenção intensiva e dispendiosa é total. Dentre tais estruturas podemos citar grandes edifícios, grandes avenidas, túneis de transporte público, passarelas de pedestres, entre outras. (Foto 7)

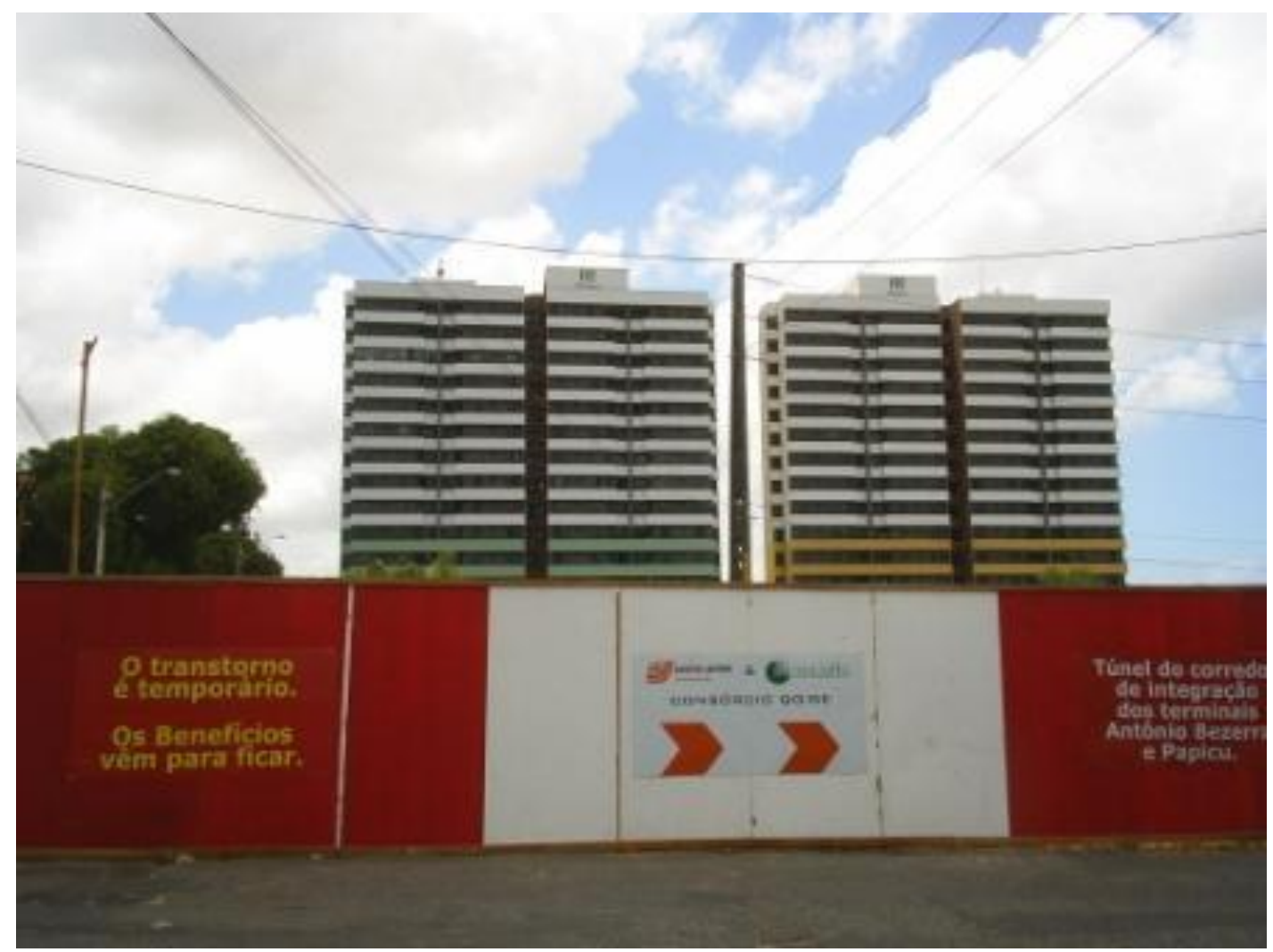

Foto 7 Imagem, ao nordeste do bairro, mostrando edificações de grande porte recém construídas (sentido da foto: SE-NW), no bairro junto a Av. Humberto Monte; em primeiro plano indicativos de melhoras no sistema de transporte público voltado a intensificação do fluxo de veículos (Bairro do Pici, Fortaleza, CE). Foto: Anderson L. G. Belem (2009). 
Os dados sobre a quantidade de área de cada classe de hemerobia estão organizados na Tabela 1 e as áreas classificadas estão mapeadas na Figura 4.

Tabela 1. Áreas e porcentagem relativa dos graus de hemerobia.

\begin{tabular}{c|c|c}
\hline Hemerobia da Paisagem & Área $\left.\mathbf{( m}^{\mathbf{2}}\right)$ & Porcentagem Relativa (\%) \\
\hline Mínima & $143.273,82$ & 3,77 \\
\hline Muito baixa & $462.377,79$ & 12,14 \\
\hline Baixa & $820.479,89$ & 21,57 \\
\hline Média & $265.920,48$ & 6,99 \\
\hline Alta & $606.149,90$ & 15,93 \\
\hline Muito alta & $1.342 .432,07$ & 35,29 \\
\hline Máxima & $163.843,57$ & 4,31 \\
\hline Total do bairro & $3.804 .477,53$ & 100,00 \\
\hline
\end{tabular}

Org.: Anderson Luiz Godinho Belem, 2010.

Com base na tabela 1 e na figura 4, pode-se constatar que mais de $55 \%$ do bairro estão com uma alta dependência tecnológica e energética para a manutenção da funcionalidade, apresentando paisagens com baixa capacidade de auto-regulação e com pouca conexão com a dinâmica dos valores naturais. As superfícies são impermeabilizadas e a vegetação, quando existente, não apresenta características de remanescente, a flora, em sua grande maioria, é composta por espécies exóticas e com poucos representantes da fauna silvestre. Essas áreas estão representadas na figura 4 pelas cores vermelha, marrom e preta e compõem as paisagens ao redor do Campus da UFC.

Apenas $15 \%$ da área do bairro se apresentam com muito baixa ou mínima hemerobia, sendo caracterizados por apresentarem paisagens com baixa dependência tecnológica e energética para a manutenção da funcionalidade, alta capacidade de auto-regulação, alto aproveitamento das funções da natureza, superfícies permeáveis, vegetação original e flora/fauna nativa. Na figura 4 podem ser observadas nas cores verde, concentradas na 
porção nordeste do Campus da UFC, e com poucas paisagens dispersas em outras partes do Campus, não sendo encontradas em nenhuma outra parte do bairro.

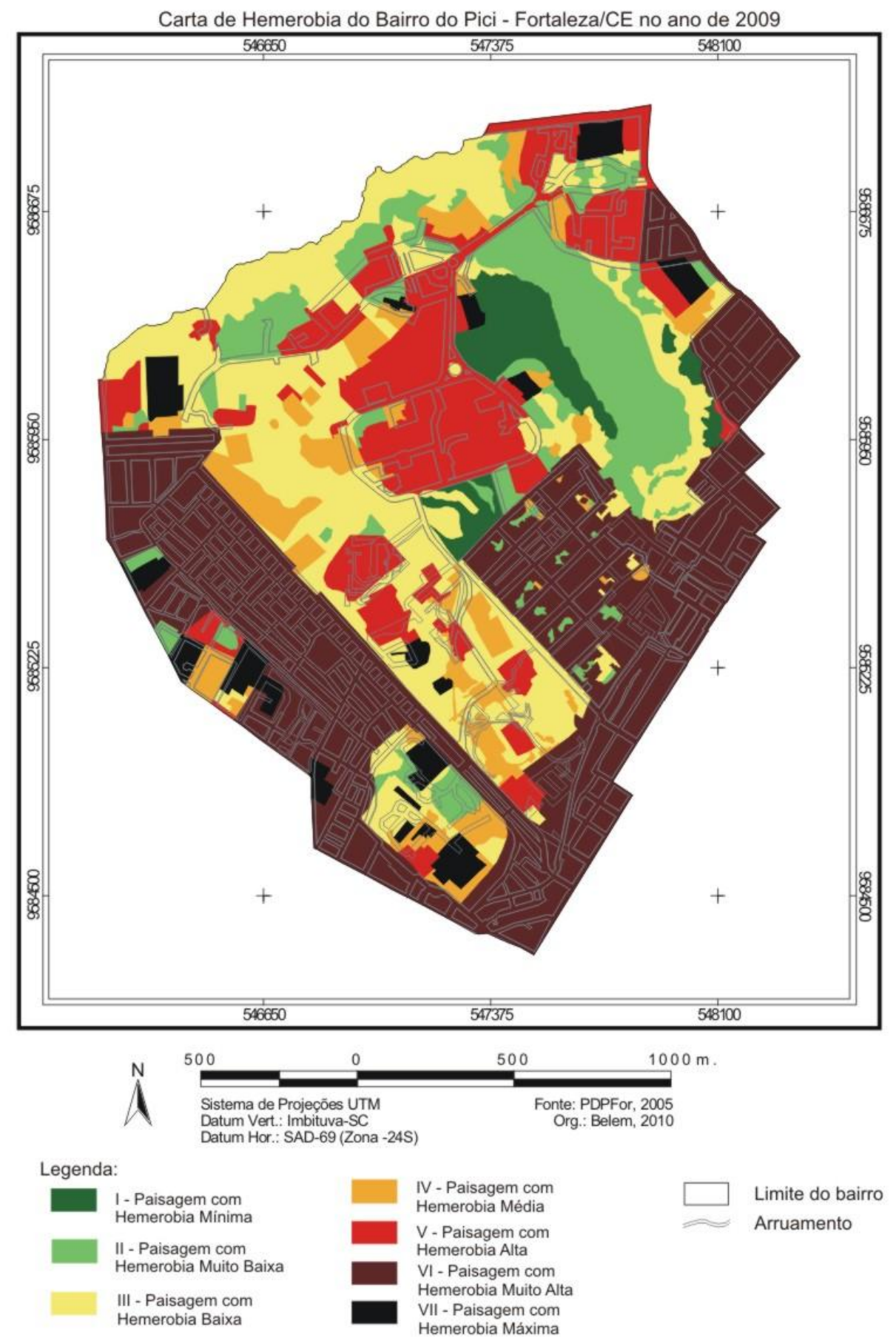

Figura 4. Carta de hemerobia do bairro do Pici, Fortaleza - CE Autoria e Org.: Anderson Luiz Godinho Belem, 2010. 
Os restantes $30 \%$ da área, encontram-se nas categorias baixa/média hemerobia, nas cores amarela e laranja, também existentes, em sua maior parte, nas áreas do Campus da UFC. (Figura 4)

As categorias de hemerobia baixa, muito baixa e mínima, perfazem 37\% da área, e estão relacionadas aos terrenos da UFC e da CAGECE. A área da CAGECE se encontra constantemente fechado e a entrada de pessoas é controlada, já o Campus da UFC possui um controle menos rígido que permite a passagem de qualquer pessoa por dentro da área.

Porém, as paisagens com hemerobia baixa (21\%), segundo verificação em campo, se tornarão áreas edificadas elevando o índice de edificações dispersas que são característicos das ocupações da universidade. Restariam assim, com graus hemerobióticos mais baixos, os 15,91\%, que pertencem a paisagens não totalmente protegidas contra a implantação de obras de expansão da universidade, sendo apenas $3,77 \%$ paisagens cercadas e protegidas.

Outra relação conveniente é a presença da Avenida Mister Hull ao norte e a Avenida Eng ${ }^{\circ}$. Humberto Monte a nordeste (Figura 4), que apresentam uma ocupação residencial com algumas áreas com o grau máximo de hemerobia e que tendem a aumentar seus tamanhos com a construção de novos edifícios devido a característica de boa localização (serviços), com infraestrutura implantada. Hoje a Mister Hull já está consolidada e a Av. Eng ${ }^{\circ}$ Humberto Monte está em processo de ampliação e construção de um túnel para transporte coletivo.

\section{CONCLUSÕES}

O bairro do Pici, graças ao Campus da UFC e a área ocupada pela CAGECE, ainda apresenta paisagens com baixo grau de hemerobia, porém 
corre o risco de ter a hemerobia aumentada graças a introdução de construções e edificações nessas paisagens.

Por outro lado, se paisagens do bairro podem ser edificadas, elas também poderiam ser re-naturalizadas, ou seja, terem sua hemerobia diminuída, apesar de ir contra a tendência de crescimento apresentada, principalmente, pelos campi das universidades federais, graças a incentivos do governo federal como o Programa de Apoio a Planos de Reestruturação e Expansão das Universidades Federais (Reuni), que vem liberando, de uma única vez, montantes de verbas suficientes para a construção de grandes edifícios nos campi das universidades.

A análise da hemerobia de um bairro, de forma absoluta, sem parâmetros de comparação, seja entre bairros, seja entre épocas diferentes, é muito difícil, pois ainda não temos parâmetros para julgar se o bairro deveria ter mais ou menos hemerobia. Nesse sentido, utilizar a avaliação da hemerobia como uma ferramenta técnico/científica de monitoramento ambiental, torna-se mais eficaz no momento.

Ressalta-se a importância de se realizar a avaliação da hemerobia em áreas já intensamente urbanizadas e em escalas de detalhe (1:5.000 a $1: 10.000)$, pois é possível melhorar por meio de "planos da paisagem" (BfN, 2002; HAAREN et al., 2008) a qualidade ambiental, inclusive das áreas centrais das grandes cidades.

Chama-se a atenção para o fato de que tanto a identificação de unidades de paisagem quanto a avaliação da hemerobia, como apresentada neste trabalho, são técnicas de fácil entendimento e aplicação, como pode ser demonstrado pelos trabalhos realizados por Garcia (2008) com alunos do Ensino Fundamental e Médio, o que fornece um esperança de que as próximas gerações reflitam mais antes de transformar as paisagens afastando-as do funcionamento da natureza. 
SPIRN (1995) enfatiza que “(...) é conveniente que cada cidade aprecie os valores sociais inerentes aos processos naturais e compreenda que a forma urbana e o interesse humano podem evoluir em harmonia com a natureza" ( $p$. 287)

\section{REFERÊNCIAS}

BEDÊ, L.C.; WEBER, M.; RESENDE, S.; PIPER, W.; SCHULE, W. Manual para Mapeamento de Biótopos no Brasil: base para um Planejamento Ambiental Eficiente. BENTRUP, F.; KÜSTERS, J.; LAMMEL, J.; KUHLMANN, $\mathrm{H}$. Life Cycle Impact Assessment of Land Use Based on the Hemeroby Concept. The international journal of life cycle assessment, Springer Berlin/Heidelberg, v.7, p. 339-348, n 6, 2002.

BERLIM - Berlin Digital Environmental Atlas, 2003. Disponível em $<$ www.stadtentwicklung.berlin.de/umwelt/umweltatlas/ed502_03.htm>. Acesso em: 10/04/2003.

BETTINI, V. Elementos de ecología urbana. Madri: Editorial Trotta, 1998.

BfN - Bundesamt für Naturschutz. Landscape planning for sustainable municipal development. Leipzig: German Federal Agency for Nature Conservation (Bundesamt für Naturschutz, BfN), 2002.

Brasil em Síntese, 2000. Disponível em: <http://www.ibge.gov.br/brasil_em_sintese/>. Acesso em: 02/09/2009

CAVALHEIRO, F. Urbanização e alterações ambientais. In: SANTOS, D. G. dos; NUCCI, J.C. (Orgs.) Paisagens Geográficas: Um tributo a Felisberto Cavalheiro. 1 ed. Campo Mourão: Editora da FECILCAM, 2009. v.1. p. 65-77. (e-book disponível em: http://www.fecilcam.br/editora/index.php?option=com_content\&task=blogcatego ry\&id=6\&ltemid $=12$

DE GROOT, R. S. Functions of nature: evaluation of nature in environmental planning, management and decision-making. Amsterdam: Wolters-Noordhoff, 1992, 315p.

DE GROOT, R. Functions-analysis and valuation as a tool to assess land use conflicts in planning for sustainable, multi-functional landscapes. Landscape and Urban Planning, n.75, Elsevier Publis., 2006. 175-186p.

DELPOUX, M. Ecossistema e Paisagem. Trad. M.C. Modenesi. Métodos em Questão, São Paulo: IGEOG/USP, 13:1-23, 1974.

DUEÑAS, W.A.M. Estudio integrado Del grado de antropización (INRA) a escala Del Paisaje: Propuesta metodológica y evaluación. IASCP, Colombia, $2004 . \quad$ Disponível em: <http://dlc.dlib.indiana.edu/archive/00001436/00/MartinezDuenas_Estudio_040 607_Paper266.pdf>. Acesso em: 2010. 
GARCIA, C. M. Utilização de imagens de satélite para construção da carta de Hemerobia do entorno do CEEP Newton Freire Maia, através da classificação de suas unidades de paisagens. In: 8 ENCONTRO DE USO ESCOLAR DO SENSORIAMENTO REMOTO NO ESTUDO DO MEIO AMBIENTE, São José dos Campos. Anais ..., 2008.

FÁVERO, O. A.; NUCCI, J. C.; DE BIASI, M. Hemerobia na Floresta Nacional de Ipanema, Iperó/SP: conceito e método. In: VI CONGRESSO BRASILEIRO DE UNIDADES DE CONSERVAÇÃO. 2004, Curitiba. Anais... CURITIBA: 2004. CD-ROM.

FÁVERO, O. A.; NUCCI, J. C.; DE BIASI, M. Hemerobia nas unidades de paisagem da Bacia Hidrográfica do Rio Sorocaba (SP) - desafios e oportunidades para conservação da natureza. Geografia: ensino e pesquisa, Santa Maria, v.12, p.2462-2479, 2008.

HAAREN, C., GALLER, C., OTT, S. Landscape planning. The basis of sustainable landscape development. Leipzig: Bundesamt für Naturschutz (Federal Agency for Nature Conservation), 2008.

HABER, W. Using Landscape Ecology in Planning and Management. In: ZONNEVELD, I.S.; FORMAN, R.T.T. (Eds.) Changing Landscapes: an ecological perspective. New York: Springer-Verlag, 1990, 286p.

HOUGH, M. Naturaleza y ciudad. Planificación y procesos ecológicos. Barcelona: Gustavo Gili, 1995, 315p.

IBGE - Mapa de Vegetação do Brasil, 2004. Disponível em www.ibge.gov.br KRÖKER, R. Transformação da Paisagem e estado hemerobiótico do bairro de Santa Felicidade, Curitiba/PR. Curitiba, 2008. 113p. Dissertação (Mestrado em eografia) - Programa de Pós-Graduação em Geografia, Universidade Federal do Paraná.

KRÖKER, R.; NUCCI, J. C.; MOLETTA, I. M. O conceito de hemerobia aplicado ao planejamento de paisagens urbanizadas. In: INTERNATIONAL CONGRESS ON ENVIRONMENTAL CHALLENGES OF URBANIZATION. 2005, Brasília. Anais... Brasília: 2005. 1 CD-ROM.

MATEO RODRIGUES, J. M.; SILVA, E. V. da; CAVALCANTI, A. P. B. Geoecologia das Paisagens: uma visão geossistêmica da análise ambiental. Fortaleza: UFC edições, 2007. 222p.

MCHARG, I. Design with nature. New York: Back Edition, 1971, 198p.

MONTEIRO, C.A.F. Derivações antropogênicas dos geossistemas terrestres no Brasil ealterações climáticas: perspectivas urbanas e agrárias ao problema da elaboração de modelos de avaliação. SIMPÓSIO SOBRE A COMUNIDADE VEGETAL COMO UNIDADE BIOLÓGICA, TURÍSTICA E ECONÔMICA. Anais ... São Paulo: ACIESP no15, 1978, p. 43-74.

$\mathrm{NUCCl}$ et al. 2003

$\mathrm{NUCCl}$, J. C. Qualidade Ambiental e Adensamento Urbano. 2 ed. Curitiba: $\mathrm{O}$ Autor, 2008, 150p. 
NUCCI, J. C.; FÁVERO, O. A. Desenvolvimento Sustentável e Conservação da Natureza em Unidades de Conservação: $O$ caso da Floresta Nacional de Ipanema (IPERÓ/SP).RA'E GA, Curitiba, n. 7, p. 63-77, 2003.

ODUM, E.P. Ecologia. Rio de Janeiro: Guanabara, 1983, 434p.

PEREIRA, R. C. M.; SILVA, E.V. da. Solos e Vegetação do Ceará: características gerais. In: SILVA, J.B da; CAVALCANTE, T.; DANTAS, E. Ceará: um novo olhar geográfico. 2 ed. Edições Demócrito Rocha: Fortaleza, 2007 v.1. p.189-210.

RIBEIRO, A.G. Estruturas e processos na interpretação da paisagem geográfica. Boletim de Geografia Teorética, Rio Claro, v.15, n 29-30, p. 112114, 1985.

SOUZA, M. J. N. de; MELENEU NETO, J.; SANTOS, J. de O.; GONDIM, M. S. Diagnóstico Geoambiental do município de Fortaleza: subsídios ao macrozoneamento ambiental e à revisão do Plano Diretor Participativo. Fortaleza: Prefeitura Municipal de Fortaleza. 2009. 172p.

SPIRN, A. W. 0 jardim de granito. A natureza no desenho da cidade. São Paulo: EDUSP, 1995.

SUKOPP, H.. Wandel von Flora und Vegetation in Mitteleuropa unter dem Einfluss dês Menschen. Berichte uber Landwirtschaft, Bd. 50/H.1: 112-139, 1972.

TROPPMAIR, H. (a). Ecossistemas e Geossistemas do Estado de São Paulo, mapa escala 1:2.000.000. Instituto de Geografia, USP, São Paulo, 1983.

TROPPMAIR, H. (b). Ecossistemas e Geossistemas do Estado de São Paulo. Geografia 13(25):27-36, Rio Claro, 1983.

TROPPMAIR, H. Biogeografia e Meio Ambiente. Rio Claro: edição do autor, 1989, 258p. 